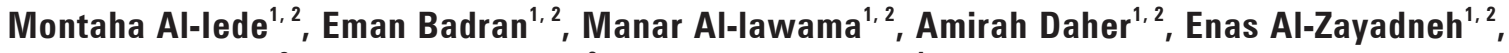
Shereen M Aleidi ${ }^{3}$, Taima Khawaldeh², Basim Alqutawneh ${ }^{4}$

'Department of Pediatrics, Jordan University Hospital, Amman, Jordan

${ }^{2}$ School of Medicine, The University of Jordan, Amman, Jordan

${ }^{3}$ Biopharmaceutics and Clinical Pharmacy, School of Pharmacy, The University of Jordan, Amman, Jordan

${ }^{4}$ Department of Radiology, Blacktown, Mount-Druitt Hospital, NSW, Australia

\section{Coronavirus disease 2019 (COVID-19): a brief overview of features and current treatment}

\begin{abstract}
Since the report of the first cases of pneumonia caused by SARS-CoV-2 in December 2019, COVID-19 has become a pandemic and is globally overwhelming healthcare systems. The symptoms of COVID-19 vary from asymptomatic infection to severe complicated pneumonia with acute respiratory distress syndrome (ARDS) and multiple organ failure leading to death. The estimated case-fatality rate among infected patients in Wuhan, the city where the first case appeared, was $1.4 \%$, with 5.1 times increase in the death rate among those aged above 59 years than those aged 30-59 years. In the absence of a proven effective and licensed treatment, many agents that showed activity against previous coronavirus outbreaks such as SARS and MERS have been used to treat SARS-CoV-2 infection. The SARS-CoV-2 is reported to be $80 \%$ homologous with SARS-CoV, and some enzymes are almost $90 \%$ homologous. Antiviral drugs are urgently required to reduce case fatality-rate and hospitalizations to relieve the burden on healthcare systems worldwide. Randomized controlled trials are ongoing to assess the efficacy and safety of several treatment regimens.
\end{abstract}

Key words: SARS-CoV-2, COVID-19, ARDS, pandemic

Adv Respir Med. 2021; 89: 158-172

\section{Introduction}

Coronavirus disease 2019 (COVID-19) is caused by a novel coronavirus (2019-nCoV) that first manifested as atypical pneumonia and was distinct from usual pneumonia in terms of symptoms and lethality. On February 11, 2020, 2019-nCoV was named severe acute respiratory syndrome coronavirus 2 (SARS-CoV-2) by the International Committee on Taxonomy of Viruses. SARS-CoV-2 is a part of a large family of RNA viruses called Coronaviridae, which has four types: Alpha, Beta, Delta, and Gamma. Coronaviruses are known to infect humans and animals, including mammals and birds. Seven coronaviruses, commonly Betacoronavirus HCoVOC43 and HCoV-HKU1, and HCoV-229E and HCoV-NL63 from Alphacoronavirus genus have been known to cause human infections [1]. Infections caused by these viruses are often mild or asymptomatic. However, severe lower respiratory tract infections have been reported, especially among patients with chronic diseases, immune system dysfunction, and at extreme ages [1,2].

Zoonotic coronaviruses have caused outbreaks in humans, namely SARS-CoV (2003, in China) and MERS-CoV (2012, in Saudi Arabia). In late 2019, COVID-19 was first reported in Wuhan City, Hubei Province, China, when a group of hospitalized patients with pneumonia of unknown etiology started to be seen [3]. SARS-CoV-2 shares viral structure and genetic sequence with both SARS-CoV and MERS-CoV of $70 \%$ and $40 \%$, respectively [4]. This new disease was declared as a global pandemic by the World Health Organization (WHO) on March 11, 2020. 
Compared to adults, the number of reported pediatric cases infected with the novel coronavirus (COVID-19) was significantly smaller [5]. Although the figure has been increasing every day, the data on children's disease clinical characteristics are still lacking. According to the clinical severity classification proposed by the COVID-19 guidelines in China, pediatric patients were more likely to have a milder clinical presentation, milder imaging findings, and less severe disease progression [6]. In adults, approximately $5 \%$ of patients will require intensive care. Information on pediatric patients needing intensive care is very limited. However, infants under 1 year appear to have an increased risk of severe disease. The infant group had the highest proportion of clinically diagnosed disease, and there remains the possibility that other viruses such as influenza A/B and respiratory syncytial virus may have caused the increased severity of the disease [7].

The pediatric multisystem inflammatory syndrome has been associated with COVID-19; this rare syndrome shares common features with other pediatric inflammatory conditions, including: Kawasaki disease, staphylococcal and streptococcal toxic shock syndromes, bacterial sepsis, and macrophage activation syndromes. It was initially described in Britain but has been reported from the US with increasing frequency. It can also present with unusual abdominal symptoms with excessive inflammatory markers. The case definition has been proposed as the following: I. A child presenting with persistent fever, inflammation (neutrophilia, elevated CRP and lymphopenia) and evidence of single or multi-organ dysfunction (shock, cardiac, respiratory, renal, gastrointestinal or neurological disorder) with additional features. This may include children fulfilling full or partial criteria for Kawasaki disease. II. Exclusion of any other microbial cause, including bacterial sepsis, staphylococcal or streptococcal shock syndromes, infections associated with myocarditis such as enterovirus. III. SARS-CoV-2 PCR testing may be positive or negative [8].

\section{Structure and pathogenesis}

SARS-CoV-2 virus has spike glycoproteins (S proteins) called peplomers. S protein is the receptor binding site and plays an important role in binding to receptors on the surface of host cells and mediating virus envelope-cell membrane fusion [9]. The S protein has two subunits, S1 and S2, and both are necessary to help the virus invading host cells. SARS-CoV-2 binds to angiotensin-converting enzyme 2 (ACE2) receptors on the targeted cells through its structural spike (S) glycoproteins S1 subunit. The virus uses a transmembrane serine protease 2 (TMPRSS2) for $\mathrm{S}$ protein priming as TMPRSS2 activates the spike and helps cleavage of ACE2.

TMPRSS2 acts on $\mathrm{S} 2$ subunit of $\mathrm{S}$ protein to facilitate the virus fusion to the cell membrane [10]. Once inside the host cells, the virus starts synthesizing RNA using its RNA-dependent RNA polymerase and viral structural proteins to complete virus formation and then virus release (Figure 1) [11].

The pathogenesis of the COVID-19 severity has not been understood yet. However, high levels of serum inflammatory cytokines such as interferon-gamma (IFN $\gamma$ ), interferon gamma inducible protein (IP10), IL-12, IL-6 and IL-1 were noted activating the Th1 cell response [12]. Patients who were critically ill, requiring an intensive care unit (ICU) had higher levels of tumor necrosis factor-alpha (TNF $\alpha)$, monocyte chemo-attractant protein (MCP1), macrophage inflammatory protein (MIP1A) and IP10 than patients who did not require ICU, which supports the relationship between cytokines storm and disease severity [12]. Xu et al. [13] have reported the result of first pathologic autopsy of a COVID-19 patient that showed a diffuse alveolar injury and hyaline membrane formation supporting ARDS diagnosis. In addition, the pathological changes seen were similar to MERS and SARS [13]. Flow cytometry revealed a significant reduction in $\mathrm{CD} 4+$ and CD8+ T lymphocytes counts in peripheral blood, which affects the immune defense mechanism. However, these T lymphocytes are in an overactive condition as manifested by high Th17 counts and an increased cytotoxicity of CD8 + T lymphocytes leading to a significant immune tissue injury in the patient's lungs and perhaps to the multisystem dysfunction [14]. This has provided a clue for COVID-19 treatmentby using agents directed against Th17 activity (Th17 inhibitors), however, this needs more research to further investigate Th1 and Th2 response in patients with COVID-19 to better understand the disease pathogenesis.

\section{Epidemiology and clinical presentation}

Since the initial SARS-CoV-2 virus detection, more than 68 million cases of COVID-19 have been confirmed worldwide, with the majority of cases reported in the United States [15]. Accord- 


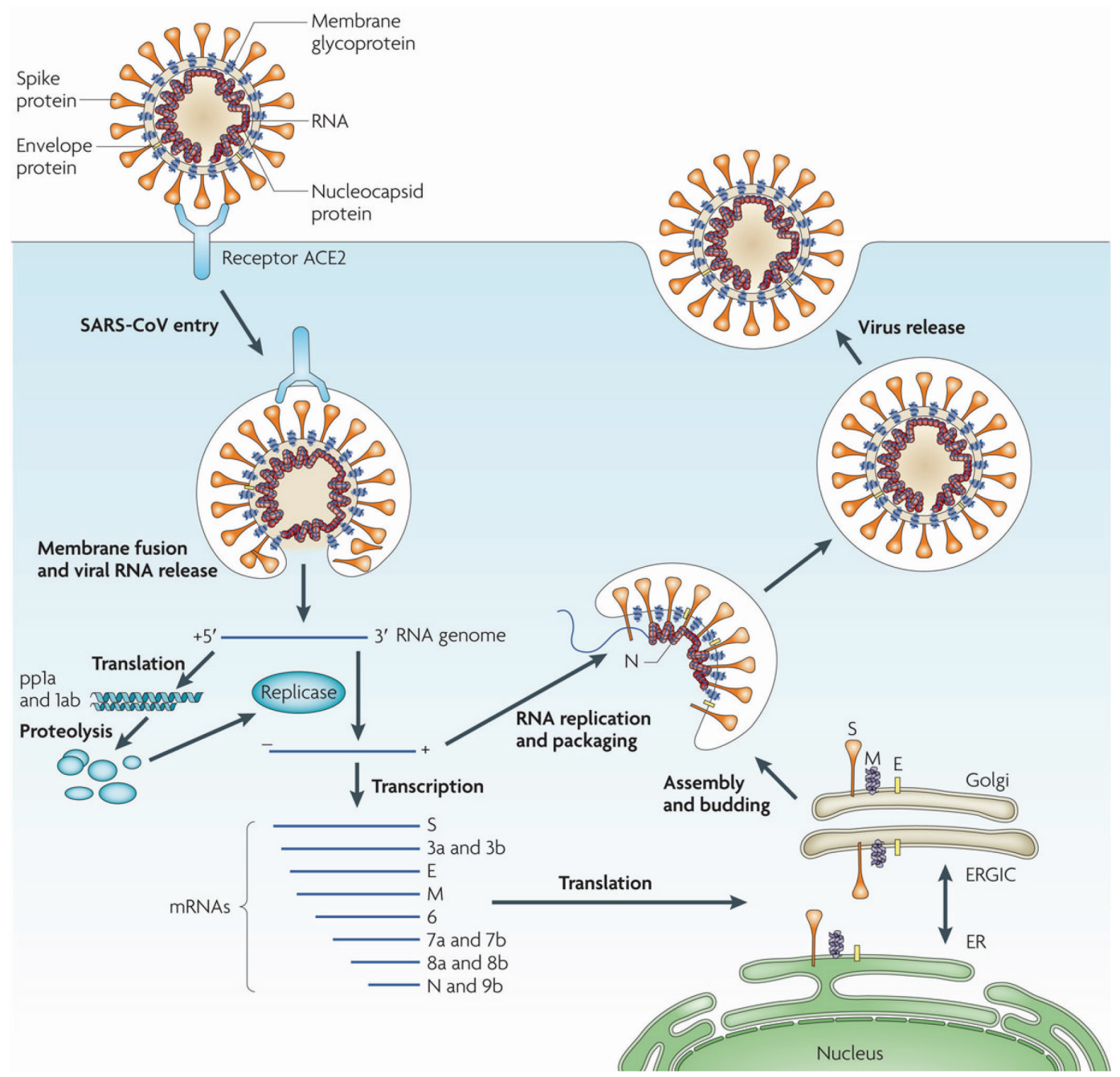

Figure 1. SARS-CoV's life cycle within the host cells. SARS-CoV-2 binds to host ACE2 via spike protein(s). Then cleavage of S protein is facilitated by host transmembrane protease TMPRSS to activate membrane fusion. A released viral genome is translated into nonstructural polyproteins which are processed by viral proteases to create the replicase. This replicase is used to produce several copies of strands and subgenomic mRNAs that are translated by ribosomes into structural proteins. The negative-strand RNA is packaged by structural protiens, followed by budding into endoplasmic reticulum-Golgi intermediate compartmetn's lumen. Finally, the viron is released as an exocytic vesicle 10 [11, with permission]

ing to a report that was published by the Chinese center for disease control and prevention on February 11,2020 , among a total of 72,314 recorded cases, $62 \%$ were diagnosed based on a positive nasal swab for viral nucleic acid test, $22 \%$ were diagnosed based on their symptoms and history of exposures with no test performed because of insufficient capacity to test all suspected cases in China during the pandemic [16]. The majority of cases (87\%) were aged $30-79$ years, $3 \%$ -80 years or older, and only $2 \%$ were younger than 19 years [16]. In terms of disease severity, the majority of cases (81\%) were labelled as mild cases that included patients with no pneumonia or mild pneumonia. Around 14\% of the cases who had symptoms that suggest significant respiratory compromise such as difficulty of breathing, tachypnea (respiratory rate $>30 / \mathrm{min}$ ), hypoxemia with a saturation of blood oxygen less than 93\%, with or without the presence of lung infiltrates on chest x-ray were considered as severe. And $5 \%$ of the total recorded cases were diagnosed to have a critical illness due to the presence of respiratory failure, hemodynamic instability, with/without multiple organ failure [16]. A possible explanation for the significant deterioration in the patients who become critically ill is thought to be due to a cytokine storm, which is a situation where there is an overproduction of cytokines that consequently leads to mutli-organ dysfunction and failure resulting in death [17].

Patients with COVID-19 typically have flulike symptoms such as a fever and a dry cough. However, old patients and those with chronic 
medical conditions and comorbidities may present with symptoms that suggest lower respiratory tract infection (pneumonia) such as chest pain, chest tightness and shortness of breath. Huang et al. [18] first reported symptoms related to COVID-19 among 41 hospitalized patients; fever (98\%), cough (76\%) and myalgia (44\%) were the most common three symptoms observed. Other symptoms such as headache, sputum production, hemoptysis and diarrhea were less frequent [18]. However, some patients predominantly presented with sneezing, rhinorrhea and sore throat. More than half of the infected patients developed dyspnea [18]. Chen et al. [19] reported 99 patients with a confirmed SARS-CoV-2 infection diagnosed by rRT-PCR. Most subjects had fever and cough, $(82 \%)$ and (81\%), respectively. Other reported symptoms were difficulty of breathing, headache, chest pain and diarrhea. Furthermore, Wang et al. [20] noted symptoms among 138 hospitalized patients with confirmed COVID-19 - fever was the main symptom (98.6\%), followed by fatigue (69.6\%) and then dry cough (59.4\%). Despite being the most commonly reported symptom, fever can be absent in early stages of the illness. A recently published systematic review showed that $36 \%$ of 3,470 confirmed cases of COVID-19 had no fever at the onset of symptoms [14].

Mao et al. reported neurological manifestations of COVID-19 among 214 hospitalized patients, with hypogeusia and hyposmia in $5.6 \%$ and $5.1 \%$ of the subjects, respectively [21]. The clinical course of COVID-19 disease displays a wide spectrum of progression patterns. Looking at the timeline of the infected cases from the onset of the disease, a median time of 8 days was noticed to develop dyspnea, 9 days to develop ARDS and 10.5 days to require mechanical ventilation [12]. Severely ill patients with ARDS may quickly progress to multiple organ failure leading to death [22]. Lymphopenia is one of the clinical features of COVID-19 infection, which indicates an immunity suppression that may result in severe complications due to secondary bacterial and fungal infections. Huang et al. [18] in their screening study of 41 patients with COVID-19, observed that 26 (63\%) of them had lymphopenia and $13(32 \%)$ patients required ICU. The subjects admitted to ICU had higher plasma levels of interleukins (ILs-2, 7 and 10), granulocytes-macrophage colony-stimulating factor (GM-CSF) and tumor necrosis factor alpha (TNF- $\alpha$ ).

The rise in inflammatory markers is the key point underlying the multisystem inflammatory response in COVID-19 [23]. The main inflam- matory and immune markers correlating with COVID-19 disease include CRP, ESR, serum ferritin, IL-6, IL-8, IL-10, and low count of lymphocytes, T cell, B cell and NK cell [23].

\section{Transmission of SARS-2}

Based on what has been reported about previous outbreaks caused by SARS and MERS, droplets are considered the main mode of transmission. Close contact with an infected person can also transmit the infection. In addition, airborne transmission has been suggested especially when invasive respiratory procedures are performed such as endotracheal intubation [24]. The gastrointestinal symptoms that have been reported with infected patients are related to invade ACE2- expressing absorptive enterocytes from the ileum and colon, which suggests that the digestive system is a potential route for SARS-CoV-2 infection [25].

\section{Diagnostic testing}

\section{Detection of viral RNA by RT-PCR}

This test is the most commonly used and considered more reliable [26]. It is performed using nasopharyngeal swabs or other upper respiratory tract specimens, including throat swab or even saliva. Viral RNA in the nasopharyngeal swab is measured by the cycle threshold (Ct). The $\mathrm{Ct}$ is the number of replication cycles needed to produce a fluorescent signal, with lower Ct values representing higher viral RNA loads. The Ct becomes detectable as early as on day 1 of symptoms and peaks within the first week of the symptom onset. This positivity starts to decline by week 3 and subsequently becomes undetectable. In severe cases, however, PCR positivity may persist beyond 3 weeks after the illness onset when most mild cases will yield a negative result [27]. In a study of 9 patients, it was noted that attempts to isolate the virus in culture were not successful beyond day 8 of the illness onset, which correlates with the decline of infectivity beyond the first week even if the PCR remains positive, thus a "positive" PCR result reflects only the detection of viral RNA and does not necessarily indicate the presence of viable virus [28]. The timeline of PCR positivity is different in specimens other than nasopharyngeal swab with PCR positivity declining more slowly in sputum and stool than in nasopharyngeal specimens [28]. Wang and colleagues published a study to compare RT-PCR positivity in different types of clinical specimens 
in 205 patients with confirmed COVID-19 infection - it was highest in bronchoalveolar lavage specimens (93\%), followed by sputum (72\%), nasal swab (63\%), and pharyngeal swab (32\%) [29]. Specificity of most of the RT-PCR tests is $100 \%$ because the primer design is specific to the genome sequence of SARS-CoV-2. Occasional false-positive results may occur due to technical errors and reagent contamination.

\section{Detection of antibodies to SARS-CoV-2}

COVID-19 infection can also be proven indirectly by measuring the host immune response to SARS-CoV-2 infection. Serological diagnosis is especially important for patients with mild to moderate illness who may present beyond the first 2 weeks of the illness onset. Serological diagnosis is also becoming an important tool to understand the extent of COVID-19 in the community and to identify individuals who are immune and potentially "protected" from becoming infected. The most sensitive and earliest serological marker is the total of antibodies (IgM and IgG ELISA), which begin to increase from the second week of the symptom onset [30]. These antibodies can be found as early as on the fourth day after the symptom onset but higher levels occur in the second and third week of illness. Antibodies may have cross-reactivity with SARS-CoV and possibly other coronaviruses. Rapid point-of-care tests for detection of antibodies have been widely developed and marketed and are of variable quality. They are considered qualitative in nature and can only indicate the presence or absence of SARS$\mathrm{CoV}-2$ antibodies but don't confirm the presence of neutralizing antibodies which can only be confirmed by a plaque reduction neutralization test. However, high titers of IgG antibodies detected by ELISA have been shown to positively correlate with neutralizing antibodies [31]. The long-term persistence and duration of protection conferred by the neutralizing antibodies remains unknown.

\section{Radiological changes of COVID-19 pneumonia}

Chest X-ray and CT scan are used for early detection of COVID-19 pneumonia. Chen et al. [18] reported bilateral pneumonia among $75 \%$ of their cohort (99 patients with COVID-19) based on chest X-ray and chest CT scan. A quarter of patients were diagnosed with unilateral pneumonia and only $14 \%$ showed a ground-glass appearance on their images. In addition to rRT-PCR, the use of chest imaging as a diagnostic and management tool of COVID-19 is still debatable as chest X-ray in adults has been found to be insensitive in mild or early COVID-19 infection [32]. Similarly, reported cases of children with COVID-19 showed completely normal X-ray on admission [33, 34]; however, in severe and more advanced cases, chest X-ray images were abnormal with bilateral multiple consolidation [35]. Jiehao et al. [36] reported multiple patch-like shadows on chest X-ray images of 4 (40\%) out of 10 infected children.

Compared to X-ray, a CT scan was shown to be more sensitive in detecting early changes and progression of the disease [37]. In fact, abnormal CT scans have been used to diagnose COVID-19 in suspected cases who initially tested negative on RT-PCR but eventually had positive tests on repeated testing $[38,39]$.

The main radiological changes seen on chest CT scans of infected patients were bilateral ground-glass opacities [12]. In children, the typical CT findings were unilateral or bilateral subpleural groundglass opacities as well [33, 40-46]. Other studies have reported findings of consolidations with and without air bronchogram and pleural effusion [35, 44, 45]. Furthermore, consolidations with surrounding halo sign were noticed in $50 \%$ of cases in a study conducted in children by Xia et al. [43]. Moreover, findings such as peribronchial distribution and bronchial thickening were more commonly seen in pediatric patients compared to the adult population [47].

In addition to its role in diagnosis, a high-resolution CT scan (HRCT) was shown by Liu et al. [48] to be useful as a potential screening tool as they used it to screen for COVID-19 in five pediatric suspected cases, and it showed multiple ground-glass opacities. However, currently, the society of Thoracic Radiology and the American College of Radiology do not support the use of chest CT for routine screening of COVID-19 [49]. However, Ji et. al. [50] reported two pediatric cases whose CT scans were completely normal [50].

Ultrasound (US) has an essential role in differential diagnosis assessment and follow-up of hospitalized patients with COVID-19, especially in intensive care units, where access to CT scan is difficult [51]. However, ultrasound should not be used to replace CT scan [52]. Lung ultrasound can be applied to evaluate many pulmonary conditions such as pleural effusion, atelectasis, consolidations, pleural effusions and pneumothorax. In COVID-19 patients, US allows evaluating the parenchyma inflammation progression, pleural thickening, and subpleural consolidations with or without air bronchograms [52]. 


\section{Case fatality}

Estimating the lethality of COVID-19 disease is challenging [53]. The case-fatality ratio is used to assess the severity of a disease and effectiveness of a treatment [54]. To calculate the CFR, the number of known deaths over a certain period of time is divided by the number of confirmed cases (including deaths and recovered cases) during that time [54]. The CFR does differ from mortality rate which is another measure of death that reflects the portion of a population who dies during a certain period of time. To get an accurate CFR, the true number of infected patients is needed. This means that the CFR can be overestimated if the true number of infected persons is underestimated. Especially, if asymptomatic and mildly symptomatic infected patients do not present to hospitals. Moreover, CFRs can differ between different geographical areas, a reason being different medical services and facilities during the pandemic period [53], the use of inappropriate statistical methods and techniques [54], in addition to the sensitivity and specificity of serologic testing that is used to confirm infection [54].

Wu et al. [55] reported a total of 72,314 infected cases with COVID-19 recorded by the Chinese center for disease control and prevention, the overall CFR till February 24, 2020 and among the confirmed 44,672 cases, was $2.3 \%$. There were no deaths recorded in children aged 9 years or younger. However, the CFR was up to $8 \%$ among the group of patients aged 70-79 years and even higher $(14.8 \%)$ in the group of older patients ( $\geq 80$ years). The CFR was the highest in the group of patients with critical illness (49\%) [55]. In a recently published systematic review, the overall CFR was 3.7\% (3,015 died of 80,565 patients) [14].

\section{Treatment}

\section{Repurposed drugs to treat SARS-CoV-2}

Currently, there has been no potential therapy shown from randomized clinical trials to improve outcomes or to significantly reduce case-fatality rate among either suspected or confirmed cases of COVID-19. However, the researchers have used drugs targeted at the virus lifecycle steps, viral entry and immunity regulation pathways to provide drug therapy for COVID-19 [56]. Because of the critical need for effective therapies, there has been a clear interest in repurposing available agents for immediate use.
Various drugs that were active against SARS$\mathrm{CoV}$ and MERS-CoV have been considered as potential therapy to treat COVID-19.

\section{Chloroquine and hydroxychloroquine}

Chloroquines have been used as antimalarial agents for decades [57]. Because of their immune-modulatory properties, these agents have been considered to treat autoimmune diseases such as rheumatoid arthritis [57]. Chloroquine (CQ) and hydroxychlorquine (HCQ) have a potential antiviral activity against SARS-CoV-2 by blocking several steps required for viral entry to host cells, including host cell receptor terminal glycosylation, proteolytic processing and edosomal acidification [58], in adition to their immune-modulatory properties through inhibition of cytokine production and host cells lysosomal activity [59], both CQ and HCQ affect the viral entrance to the host cell through inhibiting ACE2 receptor binding to viral S protein by impairment of terminal glycosylation of ACE2 on host cells, and inhibiting membrane fusion and uncoating [59]. Once inside the cell, CQ and HCQ concentrate inside the acidic organelles, such as lysosomes, endosomes and Golgi apparatus. Thus, using either CQ or HCQ therapy elevates the PH of the organelle that virus uses to replicate, which may negatively influence the viral entrance [60]. Lysosomal proteases play a role in fusion process between the viral membrane and the host, alkalinization of lysosomes will negatively affect proteases activity causing impairment of fusion process [60]. Preventing virus-host fusion helps blocking the infection. Vincent et al. studied the efficacy of CQ on SARS-CoV infection and observed inhibition of SARS-CoV spread in cells treated with CQ prior and after the infection [60]. Thus, they suggested its prophylactic and therapeutic role.

Moreover, Gautret et al. reported a 70\% viral clearance among 20 infected patients who were treated with HCQ at the sixth day of therapy. The authors also reported an increase in the viral clearance up to $100 \%$ after adding azithromycin to HCQ in 6 patients, which supports using this regimen to reduce the length of hospital stay [61]. However, the small size of the patients used azithromycin in this study (6 subjects), and were observed only for a short time (6 days), and taking into consideration the additive risk of developing cardiac complications, mainly QT prolongation with the combined therapy [61], they have encouraged to perform randomized controlled trials to assess this regimen's efficacy. 
In addition, surviving sepsis campaign guidelines on the management of critically ill adults with COVID-19 that have been published recently, provided no evidence to support this combination of therapy use in treatment of critically ill patients admitted to ICU [62]. This could be, though, due to multiple organ failure that critically ill patients have, which can influence the metabolism of these agents, and can potentially increase the risk of side effects. Whether to continue using QCs or to stop, RCTs are required. The solidarity and the discovery study are multicenter studies ongoing to provide a better understanding of antimalarial and other antiviral agents' effects.

\section{Safety and side effects}

Both CQ and HCQ are distributed well throughout body systems after oral administration and are cheap. The main side effects of these agents include diarrhea and vomiting [59]. Other serious side effects have been reported following a chronic use such as retinopathy and cardiomyopathy [63]. Moreover, toxicity due to CQ therapy has been seen in patients treated with high doses exceeding the therapeutic dosage limits. In contrary, HCQ is associated with fewer side effects than CQ because of its lower level of tissue accumulation [63]. In contrast to HCQ, CQ is considered unsafe to be given during pregnancy due to its teratogenic effect on the fetus. This supports using HCQ rather than CQ in treating pregnant women with SARS-CoV infection. HCQ can cause QT interval prolongation leading to torsade de pointes in some individuals. Despite being rare, this side effect can by amplified by using other drugs such as azithromycin that has been suggested to be used in combination with HCQ [62].

\section{Lopinavir/ritonavir combination}

The HIV antiretroviral combination lopinavir/ritonavir that is called Kaletra or Aluvia [64] as been used to treat patients with COVID-19. Lopinavir and ritonavir are protease inhibitors that have shown some activity against SARS-CoV-2 in vitro, however currently, there is no strong evidence of benefit to use it against COVID-19 [65]. Lopinavir inhibits the activity of 3-chymotrypsin-like protease (3CL) which has a role in viral RNA processing. Ritonavir inhibits the metabolizing enzyme cytochrome P450 3A and that increases the half-life of lopinavir, subsequently, affecting viral replication and release from host cells [66]. Previous studies investigating the activity of lopinavir/ritonavir against SARS and MERS were limited, still they showed a decrease in incubation period and mortality rate [67]. Up till now there has been no published data for this combination supporting its use for SARS-CoV-2. Cao et al. investigated the efficacy of Kaletra through conducting a randomized, controlled, open-label study. A total of 199 patients were included, 99 subjects were allocated to the lopinavir/ritonavir group, and the rest (100 patients) to the supportive care group [67]. The results, unfortunately, were not promising, and there were no benefits observed with lopinavir/ritonavir therapy over supportive care. In a different study from China, the authors have investigated the risk factors for prolonged SARS-CoV-2 shedding among 120 patients confirmed to have COVID-19 using tRT-PCR. They have reported a shorter median duration of viral shedding with early administration, within the first 10 days from the symptoms onset, of lopinavir/ritonavir treatment by 6.5 days [64]. However, reported serious adverse effects such as induced transaminase elevation and hepatotoxicity, limit this therapy in treating patients with COVID-19, especially those with liver injury [68]. At present, there is a lack of evidence to recommend the use of this combination for treatment of COVID-19, and more RCTs are required to assess the efficacy and safety of this therapy.

\section{Ivermectin}

Ivermectin is an FDA-approved anti-parasitic drug which has shown an antiviral effect on human immunodeficiency virus (HIV) [69]. It is known to inhibit the interaction of integrase protein (IN) of HIV-1 and the importin (IMP) $\alpha / \beta 1$ heterodimer that is important for IN nuclear transportation of viral proteins [70]. As this process is important for viral replication cycle, affecting the nuclear import can be considered as a therapeutic approach against RNA viruses. Recently, a group of Australian researchers have shown an in vivo activity with capability of ivermectin to significantly reduce the virus replication within two days [70]. Further research is required to evaluate ivermectin`s efficacy on treating SARS-CoV-2 infections.

\section{Remdesivir}

Remdesivir, which is known as GS-5743, has a broad-spectrum antiviral activity against RNA viruses such as filoviruses, pneumoviridae and paramyxoviruses [71], it has shown an in vitro activity against reported cases infected with 
SARS-CoV-2 [72]. Remdesivir is intracellulary metabolized to adenosine triphosphate analogue that blocks viral replication by inhibiting the viral RNA polymerases [73]. Initial animal experiments showed some activity against Ebola virus, however, a recent randomized controlled trial in the Democratic Republic of the Congo (DRC) showed that remdesivir was less effective in reducing mortality compared to single and triple monoclonal antibody-based treatments. However, this trial has proven the safety of its use in humans, which led the researcher to consider using it in COVID-19 clinical trials [74]. Recently, Williamson et al. have shown that remdesivir treatment was effective in reducing lung damage and disease progression in infected rhesus macaques monkeys with SARS-CoV-2 [75]. Moreover, Grein et al. have published their experience with compassionate remdesivir treatment in 53 patients with severe COVID-19, as a 10-day course of remdesivir at a dose of $100 \mathrm{mg}$ intravenously proceeded by a loading dose of $200 \mathrm{mg}$ used and followed up for 28 days. A clinical improvement in terms of respiratory support was observed in 36 (68\%) patients [76]. Remdesivir is currently being tested in clinical trials in different countries, two of these trials are randomized phase 3 trials in China.

\section{Favipiravir}

Similar to remdesivir, favipiravir inhibits the RNA polymerase activity affecting viral replication [77]. Favipiravir (FPV) is one of the medications approved for treating influenza. However, there has not been strong evidence to support its use to treat patients with COVID-19 compared to remdesivir [77]. Nevertheless, Cai et al. evaluated the effects of favipiravir against lopinavir/ritonavir for treatment of SARS-CoV-2. An oral favipiravir was used in a combination with an inhaled interferon- $\alpha$ for the synergistic effect of viral inhibition. Their results were promising as the patients in the FPV arm showed better clinical response in terms of viral clearance and disease progression with minimal adverse effects [78]. Consequently, in March 2020, the National Medical Products Administration of China approved FPV as the first drug to treat COVID-19.

\section{Ribavirin}

Ribavirin is a guanosine analog that affects the replication of RNA and DNA viruses. It also inhibits the production of guanosine from the guanine precursor by influencing the function of inosine monophosphate dehydrogenase which further affects virus stabilization [79]. Early administration of ribavirin has been reported to be beneficial in treating COVID-19-related pneumonia [80]. Ribavirin has been used in combination with the protease inhibitor lopinavir/ritonavir given the previously proven efficacy against SARS. Chu et al. examined the clinical response of 41 COVID-19 patients who were followed up to 3 weeks to a combination of lopinavir/ritonavir and ribavirin, compared to 111 controls who were SARS infected patients and received only ribavirin. The study subjects in the lopinavir/ritonavir and ribavirin treatment group had lower adverse clinical outcomes represented by ARDS or death compared to the control group. In addition, a reduction in both steroid use and nosocomial infections were noticed as well [81].

\section{Systemic glucocorticoids}

Given the high levels of cytokines that are induced by COVID-19, corticosteroids have been used for their anti-inflammatory effect to treat critically ill patients. However, current research suggested no reduction in mortality rate, but delayed viral clearance and high viral load [82, 83]. However, there is an argument for using systemic corticosteroids in patients who develop ARDS as a complications of COVID-19 infection, where in this setup it seems that they decrease the duration of mechanical ventilation and hospital mortality [84].

Corticosteroids were widely used during SARS-CoV outbreak due to their ability to modulate the inflammatory response [85]. At present, there is no clear evidence for or against corticosteroid use in the treatment of SARS-CoV-2 patients. There is some proof that corticosteroid use during early phase of infection may be beneficial [85]. However, corticosteroid should be applied carefully until further evidence that is specific to SARS-CoV-2 infection emerges.

\section{Intravenous immunoglobulin (convalescent plasma therapy)}

Immunocompromised patients and individuals with immunological disorders appear to be at higher risk of developing serious complications related to COVID-19 disease compared to healthy individuals. Immunotherapy using immunoglobulin $\mathrm{G}$ ( $\mathrm{IgG}$ ) could be used in combination with antiviral agents to treat COVID-19 and to strengthen patients' immune response against 
SARS-CoV-2 [86]. Hofmann et al. reported that sera from healthy individuals contain anti-coronavirus antibodies [87]. In addition, Pyrc et al. in a study on HCoV-NL63, showed that the infection caused by HCoV-NL63 can be inhibited by human sera from healthy adults [88]. Boukhvalova et al. reported an improved outcome of RSV infections among immunocompromised patients who were treated with IV Ig obtained from previously infected donors who had a high-titer antibodies against RSV [89]. Thus, immunotherapy using immune IgG antibodies collected from adults recovered from SARS-CoV-2 infection could be a promising modality of treatment for patients with COVID-19. It has been reported that immune IgG antibodies are more efficient in terms of virus neutralization, if collected from patients who live in the same city because of the effect of lifestyle and environmental factors on specific antibodies development against viruses [86]. Using immune IgG antibodies against SARS-CoV-2 infection can help newly infected patients by boosting their immune response to the infection. Thus, a combination of antiviral drugs and immunotherapy can be used as an alternative treatment for COVID-19 until a vaccine is developed.

\section{Interleukin (IL)-6 pathway inhibitors}

IL-6 is one of the key cytokines produced by activated macrophages. In their systematic review, Coomes et al. demonstrated significantly higher serum levels of IL-6 in patients requiring ICU admissions than non-ICU patients, suggesting that serious complications of COVID-19 can be related to a host immune response and autoimmune damage [90]. Furthermore, Zhou et al. reported a correlation between the serum levels of IL-6 and the mortality in patients with COVID-19 [91]. IL-6 is important for production of T helper 17 (Th17) cells. Excessively activated Th17 cells reported in patients with COVID-19 can be explained by the high levels of IL-6 [92]. Elevated levels of IL-6 negatively impact the lung elasticity and are associated with severe bronchoalveolar inflammation [13]. Thus, using agents that inhibit the cytokine pathway at the level of IL-6, such as tocilizumab can be beneficial in managing inflammatory response squeals. Tocilizumab (TCZM) is a recombinant monoclonal antibody that binds to both soluble and membrane-bound receptors [93]. Tocilizumab is not approved for COVID-19 treatment. However, clinicians are using it under emergency use authorization [93]. There is limited high-quality published evidence for IL-6 inhibitor use against COVID-19 [94]. However, a very recent systematic analysis that included sixteen case-controlled and eighteen uncontrolled studies revealed positive evidence for the potential efficacy of TCZM to treat severe cases of COVID-19 [93]. The World Health Organization (WHO) recommends the use of IL-6 inhibitors only in clinical trials. But, many organizations have included IL-6 inhibitors as an option for treating COVID-19 patients with severe disease [94]. Other IL-6 inhibitors such as sarilumab and siltuximab have been evaluated for the management of COVID-19 patients, with no strong evidence to be used in the management of COVID-19 patients [94].

\section{Amantadine}

Amantadine is a drug used to treat Parkinson's disease. It could be used to mitigate COVID-19 effects; the researches have shown that patients with Parkinson's disease who are treated with amantadine and have been infected with SARS-CoV-2 virus have been asymptomatic [95]. Its proposed mechanism of action is that it blocks the early stages of viral replication. Moreover, it is hypothesized that amantadine prevents the release of the viral nucleus into the cell cytoplasm by blocking the viroporine channel of SARS-CoV-2 [96]. Very recently, Jiménez-Jiménez et al. studied the anti-inflammatory effects of amantadine and its therapeutic influence in treating COVID-19. They have suggested two pharmacological effects: antiviral and anti-inflammatory [97]. Furthermore, Abreu et al. have proposed that early use of amantadine could mitigate COVID-19 disease consequences [96]. Further randomized clinical trials are required to prove its usefulness in COVID-19 management.

\section{Systemic anticoagulation}

Researchers in several centers caring for adult patients with severe COVID-19 disease noted an increased incidence of thromboembolic events. Those patients typically required ICU admission and mechanical ventilation. Two studies looked at the use of systemic anticoagulation and the impact on in-hospital mortality and reported improved outcomes [98, 99]. In an updated recommendation, the NIH in the US added the use of systemic anticoagulants in its recommendations for the care of hospitalized 
critically ill adult patients with COVID-19 [100]. One of the anti-coagulant agents that were tried on COVID-19 patients is sulodexide. It is a natural glycosaminoglycan composed of fast-moving heparin (80\%) and dermatan sulfate (20\%) [101]. It has an arterial and venous anti-thrombotic action and ani-inflammatory activity through suppression of IL-6 production [101]. Compared with low-molecular-weight heparin (LMWTs), sulodexide is associated with less bleeding risk and is safe to be given to patients with renal insufficiency [102]. This drug may represent an alternative prophylactic agent to LMWH [102]. It was hypothesized that the early use of sulodexide in COVID-19 patients with comorbidities might reduce the severity of the disease and prevent the development of severe complications [103]. Bikdeli et al. reviewed 6 randomized controlled trials (RCTs) where the use of sulodexide was compared with placebo. The sulodexide administration was associated with a reduction in the odds ratio of cardiovascular mortality, deep vein thrombosis, and myocardial infarction [104]. However, additional RCTs with this drug are warranted.

\section{Respiratory support}

Hypoxemia is common in hospitalized COVID-19 patients. More than a quarter of the hospitalized COVID-19 subjects require intensive care due to acute respiratory failure [105]. Conventional oxygen therapy can be insufficient to meet oxygen needs of individuals with acute hypoxic respiratory failure [106]. Options for treating hypoxic patients, other than conventional oxygen therapy, include high-flow nasal cannula (HFNC), noninvasive positive-pressure ventilation (NIPPV), or intubation and invasive mechanical ventilation. Based on meta-analysis and data from non-COVID-19 clinical trials that showed reductions in the need for intubation in patients who received HFNC or NIPPV, these options are preferable to conventional oxygen therapy [107]. Furthermore, HFNC use is preferred over NIPPV in hypoxic patients due to acute respiratory failure [108]. Patients with COVID-19 should be monitored for signs of respiratory deterioration. Early intubation should be considered when the patients' condition deteriorates and they have additional acute system dysfunction or when HFNC and NIPPV are not available to treat the hypoxic acute respiratory failure [106]. If required, intubation should be performed by experienced staff in a controlled setting to ensure the safety of both patients and healthcare workers.

\section{Use of antibiotic therapy}

A meta-analysis of small case series reported that $3.5 \%$ of COVID-19 patients had a bacterial co-infection, and $14 \%$ had a secondary bacterial infection [109]. Superimposed bacterial infections have been reported in $28 \%$ of severely infected and critically ill COVID-19 patients, which may support the antibiotic use in intensive care units [110]. Despite the lack of reported cases of initial superinfections, there is widespread use of antibiotics in hospitalized COVID-19 patients. Antibiotic use in patients with COVID-19 has not been shown to affect clinical outcomes. Contrary, unnecessary antibiotic use has been associated with an increased risk of resistant hospital-acquired bacterial and fungal infections [111]. Antibiotic therapy is not recommended for COVID-19-related pneumonia unless a secondary bacterial infection is suspected.

\section{Vaccine development}

Since the full genomic sequence of SARS-CoV-2; the cause of the novel coronavirus pandemic (COVID-19) has been published [112], many countries, institutions, and pharmaceutical companies started racing to develop an effective and safe vaccine, as it's the most reliable and cost-effective method to control any emerging viral infection and flatten its transmission curve as well as to prevent any re-emergences of the disease in the future. According to the WHO, until this date, more than 40 programs are working on a vaccine against SARS-CoV-2 [113], only two of them entered the clinical trials; recombinant adenovirus vector vaccine which is in phase-2 clinical trial [114], and mRNA-based vaccine in phase-1 [115].

In addition to live vector and RNA-based vaccines, candidates using other platforms, such as the whole virus; either killed or live attenuated [116-118], DNA-based [119, 120], and recombinant subunit vaccines, are also under development ; which is currently getting a lot of attention since the surface $S$ glycoprotein has shown to be the main target for subunit vaccines against MERS-COV and SARS-COV [121-124], and it is expected to be the same for SARS-CoV-2 due to the reported high genetic similarities especially with SARS-COV [126, 127]. Several studies have shown that $S$ glycoprotein and its RBD fragment is an ideal vaccine target against SARCoV-2 [127-132]. To date all S glycoprotein-based vaccine candidates targeting SARS-CoV-2 are still in preclinical phase [113]. Another interesting 
subunit vaccine targets are specific $\mathrm{B}$ and $\mathrm{T}$ cell epitopes [133-135]. However, as vaccines usually take at least one year to be available, alternative options should be considered.

Existing and widely used vaccines may serve a potential protective effect against SARS$\mathrm{CoV}-2$ as it has been observed that the incidence of COVID-19 in groups who are vaccinated routinely, especially children, is very low [136, 137], and recently, it has been hypothesized that BCG vaccine may offer a protective shield against COVID-19 based on observations that compared the prevalence of COVID-19 in countries where BCG is a national program with other countries $[138,139]$. However, two clinical trials have been started to assess its efficacy in protecting healthcare workers who are in contact with COVID-19 patients [140, 141]. Another interesting short-term protection alternative option is convalescent sera which provide an immediate passive immunity by administering the collected antibodies from recovered patients in susceptible individuals $[142,143]$, thus, convalescent plasma combined with other potential therapeutic drugs may serve a good alternative treatment until strong options such as vaccines are available. As for any vaccine, in addition to the time it takes to be developed and evaluated, it also poses some challenges regarding its candidate such as antibody-dependent enhancement (ADE); a phenomenon in which the viral antigens used by the vaccine may induce the same disease they're supposed to protect from [144]. Moreover, RNA viruses; which are the big family of coronaviruses have been shown to have a higher rate of mutations when they're compared to DNA viruses $[145,146]$.

In the past, vaccines were developed through many steps that might have taken several years. Recently, given the urgent need to develop a COVID-19 vaccine, some of the vaccine development steps are happening in parallel while maintaining safety standards. For example, multiple vaccines are evaluated at the same time by some clinical trials [147]. Clinical development of a new vaccine is a three-phase process. During phase-1, small groups of healthy adult volunteers should be enrolled. In phase-2, the vaccine is given to groups of volunteers that reflect the populations for whom the vaccine is intended. In phase-3, the vaccine is given to large groups of people (thousands) to test its efficacy and safety [148]. Multiple vaccines are being tested in early-phase studies, and some vaccine participants are in phase-3 studies assessing efficacy [149].

\section{Conflict of interest}

The authors declare no conflict of interest.

\section{References:}

1. Yin Y, Wunderink RG. MERS, SARS and other coronaviruses as causes of pneumonia. Respirology. 2018; 23(2): 130-137. doi: 10.1111/resp.13196, indexed in Pubmed: 29052924.

2. Hui DS, Azhar EI, Kim YJ, et al. Middle East respiratory syndrome coronavirus: risk factors and determinants of primary, household, and nosocomial transmission. Lancet Infect Dis. 2018; 18(8): e217-e227, doi: 10.1016/S1473-3099(18)30127-0, indexed in Pubmed: 29680581.

3. Wuhan City Health Committee (WCHC) Wuhan Municipal Health and Health Commission's briefing on the current pneumonia epidemic situation in our city 2019. Available online: http:/wjw.wuhan.gov.cn/front/web/showDetail/2019123108989. [Last accessed at: 25.09.2020].

4. Zhou D, Dai SM, Tong Q. COVID-19: a recommendation to examine the effect of hydroxychloroquine in preventing infection and progression. J Antimicrob Chemother. 2020; 75(7): 1667-1670, doi: 10.1093/jac/dkaa114, indexed in Pubmed: 32196083.

5. Dong Y, Mo Xi, Hu Y, et al. Epidemiology of COVID-19 among children in China. Pediatrics. 2020; 145(6), doi: 10.1542/ peds.2020-0702, indexed in Pubmed: 32179660.

6. China National Health Commission. Diagnosis and treatment of pneumonitis caused by a new coronavirus (trial version 6). Beijing: China National Health Commission. 2020. Available online: www.nhc.gov.cn/yzygj/ s7653p/202001/4294563ed35b43209b31739bd0785e67.shtml. [Last accessed at: 25.09.2020].

7. Ong JSM, Tosoni A, Kim Y, et al. Coronavirus Disease 2019 in Critically Ill Children: A Narrative Review of the Literature. Pediatr Crit Care Med. 2020; 21(7): 662-666, doi: 10.1097/ PCC.0000000000002376, indexed in Pubmed: 32265372 .

8. Riphagen S, Gomez X, Gonzalez-Martinez C, et al. Hyperinflammatory shock in children during COVID-19 pandemic. Lancet. 2020; 395(10237): 1607-1608, doi: 10.1016/S01406736(20)31094-1, indexed in Pubmed: 32386565 .

9. Li F. Structure, function, and evolution of coronavirus spike proteins. Annu Rev Virol. 2016; 3(1): 237-261, doi: 10.1146 annurev-virology-110615-042301, indexed in Pubmed: $\underline{27578435}$.

10. Hoffmann M, Kleine-Weber H, Schroeder S, et al. SARSCoV-2 cell entry depends on ACE2 and TMPRSS2 and is blocked by a clinically proven protease inhibitor. Cell. 2020; 181(2): 271-280.e8, doi: 10.1016/j.cell.2020.02.052, indexed in Pubmed: 32142651.

11. Du L, He Y, Zhou Y, et al. The spike protein of SARS-CoV-a target for vaccine and therapeutic development. Nat Rev Microbiol. 2009; 7(3): 226-236, doi: 10.1038/nrmicro2090, indexed in Pubmed: 19198616.

12. Ye Q, Wang B, Mao J. The pathogenesis and treatment of the 'Cytokine Storm' in COVID-19. J Infect. 2020; 80(6): 607-613, doi: 10.1016/i.jinf.2020.03.037, indexed in Pubmed: $\underline{32283152 .}$.

13. $\mathrm{Xu} \mathrm{Z,} \mathrm{Shi} \mathrm{L}$, Wang $\mathrm{Y}$, et al. Pathological findings of COVID-19 associated with acute respiratory distress syndrome. Lancet Respir Med. 2020; 8(4): 420-422, doi: 10.1016/S22132600(20)30076-X, indexed in Pubmed: $\underline{32085846}$.

14. Fu L, Wang B, Yuan T, et al. Clinical characteristics of coronavirus disease 2019 (COVID-19) in China: A systematic review and meta-analysis. J Infect. 2020; 80(6): 656-665, doi: 10.1016/j.jinf.2020.03.041, indexed in Pubmed: 32283155 .

15. Worldometer: Coronavirus Update (Live). Avalable online: www.worldometers.info/coronavirus. [Last accessed at: 12.12.2020].

16. Epidemiology Working Group for NCIP Epidemic Response, Chinese Center for Disease Control and Prevention. Zhonghua Liu Xing Bing Xue Za Zhi. 2020; 41(2): 145-151.

17. Shimabukuro-Vornhagen A, Gödel P, Subklewe M, et al. Understanding cytokine release syndrome. Intensive Care Med. 
2018; 44(3): 371-373, doi: 10.1007/s00134-017-4943-5, indexed in Pubmed: 28956093.

18. Zhang H, Du F, Cao XJ, et al. Clinical features of patients infected with 2019 novel coronavirus in Wuhan, China. Lancet. 2020; 395(10223): 497-506, doi: 10.1016/S01406736(20)30183-5, indexed in Pubmed: 31986264.

19. Chen N, Zhou M, Dong X, et al. Epidemiological and clinical characteristics of 99 cases of 2019 novel coronavirus pneumonia in Wuhan, China: a descriptive study. The Lancet. 2020; 395(10223): 507-513, doi: 10.1016/s0140-6736(20)30211-7.

20. Wang D, Hu Bo, Hu C, et al. Clinical characteristics of 138 hospitalized patients with 2019 novel coronavirus-infected pneumonia in wuhan, china. JAMA. 2020; 323(11): 1061-1069, doi: 10.1001/jama.2020.1585, indexed in Pubmed: 32031570.

21. Mao L, Jin H, Wang M, et al. Neurologic manifestations of hospitalized patients with coronavirus disease 2019 in Wuhan, China. JAMA Neurol. 2020; 77(6): 683-690, doi: 10.1001/ jamaneurol.2020.1127, indexed in Pubmed: 32275288.

22. Zaim S, Chong JH, Sankaranarayanan V, et al. COVID-19 and multiorgan response. Curr Probl Cardiol. 2020; 45(8): 100618, doi: 10.1016/j.cpcardiol.2020.100618, indexed in Pubmed: 32439197.

23. Ponti G, Maccaferri M, Ruini C, et al. Biomarkers associated with COVID-19 disease progression. Crit Rev Clin Lab Sci. 2020; 57(6): 389-399, doi: 10.1080/10408363.2020.1770685, indexed in Pubmed: 32503382.

24. Bouadma L, Lescure FX, Lucet JC, et al. Severe SARS-CoV-2 infections: practical considerations and management strategy for intensivists. Intensive Care Med. 2020; 46(4): 579582, doi: 10.1007/s00134-020-05967-x, indexed in Pubmed: 32103284

25. Zhang H, Kang Z, Gong $\mathrm{H}$, et al. The digestive system is a potential route of 2019-nCov infection: a bioinformatics analysis based on single-cell transcriptomes. , doi: 10.1101/2020.01.30.927806.

26. Sethuraman N, Jeremiah SS, Ryo A. Interpreting diagnostic tests for SRASA-CoV-2. JAMA. 2020; 323(22): 2249-2251, doi: 10.1001/jama.2020.8259, indexed in Pubmed: 32374370 .

27. Zheng S, Fan J, Yu F, et al. Viral load dynamics and disease severity in patients infected with SARS-CoV-2 in Zhejiang province, China, January-March 2020: retrospective cohort study. BMJ. 2020; 369: m1443, doi: 10.1136/bmi.m1443, indexed in Pubmed: $\underline{32317267}$.

28. Wölfel R, Corman VM, Guggemos W, et al. Virological assessment of hospitalized patients with COVID-2019. Nature. 2020; 581(7809): 465-469, doi: 10.1038/s41586-020-2196-x, indexed in Pubmed: $\underline{32235945}$.

29. Wang W, Xu Y, Gao R, et al. Detection of SARS-CoV-2 in different types of clinical specimens. JAMA. 2020; 323(18): 1843-1844, doi: 10.1001/jama.2020.3786, indexed in Pubmed: $\underline{32159775}$.

30. Lou B, Li TD, Zheng SF, et al. Serology characteristics of SARS-CoV-2 infection after exposure and post-symptom onset. Eur Respir J. 2020; 56(2), doi: 10.1183/13993003.007632020, indexed in Pubmed: 32430429.

31. Wu F, Wang A, Liu M, et al. Neutralizing antibody responses to SARS-CoV-2 in a COVID-19 recovered patient cohort and their implications. , doi: 10.1101/2020.03.30.20047365.

32. Wong HoY, Lam HY, Fong AHT, et al. Frequency and distribution of chest radiographic findings in patients positive for COVID-19. Radiology. 2020; 296(2): E72-E78, doi: 10.1148/ radiol.2020201160, indexed in Pubmed: 32216717.

33. Park JiY, Han MiS, Park KUn, et al. First pediatric case of coronavirus disease 2019 in Korea. J Korean Med Sci. 2020; 35(11): e124, doi: 10.3346/jkms.2020.35.e124, indexed in Pubmed: $\underline{32193905 .}$.

34. Kamali Aghdam M, Jafari N, Eftekhari K. Novel coronavirus in a 15-day-old neonate with clinical signs of sepsis, a case report. Infect Dis (Lond). 2020; 52(6): 427-429, doi: 10.1080/23744235.2020.1747634, indexed in Pubmed: 32233816.

35. Sun D, Li H, Lu XX, et al. Clinical features of severe pediatric patients with coronavirus disease 2019 in Wuhan: a single center's observational study. World J Pediatr. 2020; 16(3): 251-259, doi: 10.1007/s12519-020-00354-4, indexed in Pubmed: 32193831.
36. Jiehao C, Jin Xu, Daojiong L, et al. A case series of children with 2019 novel coronavirus infection: clinical and epidemiological features. Clin Infect Dis. 2020; 71(6): 1547-1551, doi: 10.1093/cid/ciaa198, indexed in Pubmed: 32112072.

37. Rubin G, Ryerson C, Haramati L, et al. The role of chest imaging in patient management during the COVID-19 pandemic. Chest. 2020; 158(1): 106-116, doi: 10.1016/i. chest.2020.04.003.

38. Fang Y, Zhang H, Xie J, et al. Sensitivity of chest CT for COVID-19: comparison to RT-PCR. Radiology. 2020; 296(2): E115-E117, doi: 10.1148/radiol.2020200432, indexed in Pubmed: $\underline{32073353}$.

39. Huang P, Liu T, Huang L, et al. Use of chest CT in combination with negative RT-PCR assay for the 2019 novel coronavirus but high clinical suspicion. Radiology. 2020; 295(1): 22-23, doi: 10.1148/radiol.2020200330, indexed in Pubmed: $\underline{32049600 .}$

40. Liu H, Liu F, Li J, et al. Clinical and CT imaging features of the COVID-19 pneumonia: Focus on pregnant women and children. J Infect. 2020; 80(5): e7-ee13, doi: 10.1016/j. iinf.2020.03.007, indexed in Pubmed: $\underline{32171865}$.

41. Li W, Cui H, Li K, et al. Chest computed tomography in children with COVID-19 respiratory infection. Pediatr Radiol. 2020; 50(6): 796-799, doi: 10.1007/s00247-020-04656-7, indexed in Pubmed: $\underline{32162081}$.

42. Shen Q, Guo W, Guo T, et al. Novel coronavirus infection in children outside of Wuhan, China. Pediatr Pulmonol. 2020; 55(6): 1424-1429, doi: 10.1002/ppul.24762, indexed in Pubmed: $\underline{32259403}$

43. Xia W, Shao J, Guo Yu, et al. Clinical and CT features in pediatric patients with COVID-19 infection: Different points from adults. Pediatr Pulmonol. 2020; 55(5): 1169-1174, doi: 10.1002/ppul.24718, indexed in Pubmed: 32134205.

44. Lu X, Zhang L, Du H, et al. SARS-CoV-2 Infection in Children. N Engl J Med. 2020; 382(17): 1663-1665, doi: $10.1056 /$ NEJMc2005073, indexed in Pubmed: 32187458.

45. Hu Q, Guan H, Sun Z, et al. Initial CT findings and temporal changes in patients with the novel coronavirus pneumonia (2019-nCoV): a study of 63 patients in Wuhan, China. Eur Radiol. 2020; 30(6): 3306-3309, doi: 10.1007/s00330-02006731-x, indexed in Pubmed: 32055945.

46. Han YN, Feng ZW, Sun LN, et al. A comparative-descriptive analysis of clinical characteristics in 2019-coronavirus-infected children and adults. J Med Virol. 2020; 92(9): 1596-1602, doi: $10.1002 / j m v .25835$, indexed in Pubmed: 32249943.

47. Chen A, Huang JX, Liao Y, et al. Differences in clinical and imaging presentation of pediatric patients with COVID-19 in comparison with adults. Radiol Cardiothorac Imaging. 2020; 2(2): e200117, doi: 10.1148/ryct.2020200117, indexed in Pubmed: 33778567.

48. Liu M, Song Z, Xiao K. High-Resolution computed tomography manifestations of 5 pediatric patients with 2019 novel coronavirus. J Comput Assist Tomogr. 2020; 44(3): 311-313, doi: 10.1097/ RCT.0000000000001023, indexed in Pubmed: 32217900.

49. ACR Recommendations for the use of Chest Radiography and Computed Tomography (CT) for Suspected COVID-19 Infection.2020. Available online: www.acr.org/ Advocacy-and-Economics/ACR-Position-Statements/Recommendations-for-Chest-Radiography-and-CT-for-Suspected-COVID19-Infection [Last accessed at: 25.09.2020].

50. Ji LN, Chao S, Wang YJ, et al. Clinical features of pediatric patients with COVID-19: a report of two family cluster cases. World J Pediatr. 2020; 16(3): 267-270, doi: 10.1007/s12519020-00356-2, indexed in Pubmed: 32180140.

51. de Oliveira RR, Rodrigues TP, da Silva PS, et al. Lung ultrasound: an additional tool in COVID-19. Radiol Bras. 2020; 53(4): 241-251, doi: 10.1590/0100-3984.2020.0051, indexed in Pubmed: 32904752.

52. Farias Ld, Fonseca EK, Strabelli DG, et al. Imaging findings in COVID-19 pneumonia. Clinics (Sao Paulo). 2020; 75: e2027, doi: 10.6061/clinics/2020/e2027, indexed in Pubmed: 32578826 .

53. Battegay M, Kuehl R, Tschudin-Sutter S, et al. 2019-novel coronavirus (2019-ncov): estimating the case fatality rate - a word of caution. Swiss Med Wkly. 2020; 150: w20203, doi: 10.4414/smw.2020.20203, indexed in Pubmed: 32031234. 
54. Ghani AC, Donnelly CA, Cox DR, et al. Methods for estimating the case fatality ratio for a novel, emerging infectious disease. Am J Epidemiol. 2005; 162(5): 479-486, doi: 10.1093/aje/ kwi230, indexed in Pubmed: 16076827.

55. Wu Z, McGoogan JM. Characteristics of and important lessons from the coronavirus disease 2019 (COVID-19) outbreak in China: summary of a report of 72314 cases from the Chinese Center for Disease Control and Prevention. JAMA. 2020; 323(13): 1239-1242, doi: 10.1001/jama.2020.2648, indexed in Pubmed: 32091533.

56. Al-Bari MdA. Targeting endosomal acidification by chloroquine analogs as a promising strategy for the treatment of emerging viral diseases. Pharmacol Res Perspect. 2017; 5(1): e00293, doi: 10.1002/prp2.293, indexed in Pubmed: 28596841.

57. Savarino A, Boelaert J, Cassone A, et al. Effects of chloroquine on viral infections: an old drug against today's diseases. The Lancet Infectious Diseases. 2003; 3(11): 722-727, doi: 10.1016/s1473-3099(03)00806-5.

58. Sanders JM, Monogue ML, Jodlowski TZ, et al. Pharmacologic treatments for coronavirus disease 2019 (COVID-19): a review. JAMA. 2020; 323(18): 1824-1836, doi: 10.1001/ jama.2020.6019, indexed in Pubmed: 32282022.

59. Braga CB, Martins AC, Cayotopa AD, et al. Side effects of chloroquine and primaquine and symptom reduction in malaria endemic area (Mâncio Lima, Acre, Brazil). Interdiscip Perspect Infect Dis. 2015; 2015: 346853, doi: 10.1155/2015/346853, indexed in Pubmed: 26357512

60. Vincent MJ, Bergeron E, Benjannet S, et al. Chloroquine is a potent inhibitor of SARS coronavirus infection and spread. Virol J. 2005; 2: 69, doi: 10.1186/1743-422X-2-69, indexed in Pubmed: 16115318.

61. Gautret P, Lagier JC, Parola P, et al. Clinical and microbiological effect of a combination of hydroxychloroquine and azithromycin in 80 COVID-19 patients with at least a six-day follow up: A pilot observational study. Travel Med Infect Dis. 2020; 34: 101663, doi: 10.1016/i.tmaid.2020.101663, indexed in Pubmed: 32289548.

62. Alhazzani W, Møller MH, Arabi YM, et al. Surviving sepsis campaign: guidelines on the management of critically ill adults with coronavirus disease 2019 (COVID-19). Intensive Care Med. 2020; 46(5): 854-887, doi: 10.1007/s00134-02006022-5, indexed in Pubmed: 32222812.

63. Schrezenmeier E, Dörner T. Mechanisms of action of hydroxychloroquine and chloroquine: implications for rheumatology. Nat Rev Rheumatol. 2020; 16(3): 155-166, doi: 10.1038 s41584-020-0372-x, indexed in Pubmed: $\underline{32034323}$.

64. Choy KT, Wong AYL, Kaewpreedee P, et al. Remdesivir, lopinavir, emetine, and homoharringtonine inhibit SARS-CoV-2 replication in vitro. Antiviral Res. 2020; 178: 104786, doi: 10.1016/j. antiviral.2020.104786, indexed in Pubmed: 32251767.

65. Sheahan TP, Sims AC, Leist SR, et al. Comparative therapeutic efficacy of remdesivir and combination lopinavir, ritonavir, and interferon beta against MERS-CoV. Nat Commun. 2020; 11(1): 222, doi: 10.1038/s41467-019-13940-6, indexed in Pubmed: 31924756.

66. Zhang L, Lin D, Sun X, et al. Crystal structure of SARSCoV-2 main protease provides a basis for design of improved $\alpha$-ketoamide inhibitors. Science. 2020; 368(6489): 409-412, doi: 10.1126/science.abb3405, indexed in Pubmed: 32198291.

67. Cao B, Wang Y, Wen D, et al. A trial of lopinavir-ritonavir in adults hospitalized with severe covid-19. N Engl J Med. 2020; 382(19): 1787-1799, doi: 10.1056/NEJMoa2001282, indexed in Pubmed: 32187464

68. Kottilil S, Polis MA, Kovacs JA. HIV Infection, hepatitis C infection, and HAART: hard clinical choices. JAMA. 2004; 292(2): 243-250, doi: 10.1001/jama.292.2.243, indexed in Pubmed: 15249574.

69. Wagstaff KM, Sivakumaran H, Heaton SM, et al. Ivermectin is a specific inhibitor of importin $\alpha / \beta$-mediated nuclear import able to inhibit replication of HIV-1 and dengue virus. Biochem J. 2012; 443(3): 851-856, doi: 10.1042/BJ20120150, indexed in Pubmed: 22417684.

70. Caly L, Druce JD, Catton MG, et al. The FDA-approved drug ivermectin inhibits the replication of SARS-CoV-2 in vi- tro. Antiviral Res. 2020; 178: 104787, doi: 10.1016/j.antiviral.2020.104787, indexed in Pubmed: 32251768.

71. Gordon CJ, Tchesnokov EP, Woolner E, et al. Remdesivir is a direct-acting antiviral that inhibits RNA-dependent RNA polymerase from severe acute respiratory syndrome coronavirus 2 with high potency. J Biol Chem. 2020; 295(20): 67856797, doi: 10.1074/jbc.RA120.013679, indexed in Pubmed: 32284326.

72. Kujawski S, Wong K, Collins J, et al. First 12 patients with coronavirus disease 2019 (COVID-19) in the United States. medRxiv. 2020. Avalable online: https://www.medrxiv.org/ content/10.1101/2020.03.09.20032896v1. [Last accessed at: 12.09.2020].

73. Agostini ML, Andres EL, Sims AC, et al. Coronavirus susceptibility to the antiviral remdesivir (GS-5734) is mediated by the viral polymerase and the proofreading exoribonuclease. mBio. 2018; 9(2), doi: 10.1128/mBio.00221-18, indexed in Pubmed: 29511076.

74. Mulangu S, Dodd LE, Davey RT, et al. A randomized, controlled trial of ebola virus disease therapeutics. N Engl J Med. 2019; 381(24): 2293-2303, doi: 10.1056/NEJMoa1910993, indexed in Pubmed: 31774950.

75. Williamson BN, Feldmann F, Schwarz B, et al. Clinical benefit of remdesivir in rhesus macaques infected with SARS-CoV-2. bioRxiv. 2020; 585(7824): 273-276, doi: 10.1101/2020.04.15.043166, indexed in Pubmed: $\underline{32511319}$.

76. Grein J, Ohmagari N, Shin D, et al. Compassionate use of remdesivir for patients with severe COVID-19. N Engl J Med. 2020; 382(24): 2327-2336, doi: 10.1056/NEJMoa2007016, indexed in Pubmed: 32275812.

77. Tu YF, Chien CS, Yarmishyn AA, et al. A review of SARSCoV-2 and the ongoing clinical trials. Int J Mol Sci. 2020 21(7), doi: 10.3390/ijms21072657, indexed in Pubmed: $\underline{32290293 .}$.

78. Cai Q, Yang M, Liu D, et al. Experimental treatment with favipiravir for COVID-19: an open-label control study. Engineering (Beijing). 2020; 6(10): 1192-1198, doi: 10.1016/i. eng.2020.03.007, indexed in Pubmed: 32346491.

79. Wang M, Cao R, Zhang L, et al. Remdesivir and chloroquine effectively inhibit the recently emerged novel coronavirus (2019-nCoV) in vitro. Cell Res. 2020; 30(3): 269-271, doi: 10.1038/s41422-020-0282-0, indexed in Pubmed: 32020029.

80. Khalili JS, Zhu H, Mak NS, et al. Novel coronavirus treatment with ribavirin: Groundwork for an evaluation concerning COVID-19. J Med Virol. 2020; 92(7): 740-746, doi: 10.1002/ jmv.25798, indexed in Pubmed: $\underline{32227493}$.

81. Chu CM, Cheng VCC, Hung IFN, et al. Role of lopinavir/ ritonavir in the treatment of SARS: initial virological and clinical findings. Thorax. 2004; 59(3): 252-256, doi: 10.1136/ thorax.2003.012658, indexed in Pubmed: 14985565.

82. Arabi YM, Mandourah Y, Al-Hameed F, et al. Corticosteroid therapy for critically ill patients with middle east respiratory syndrome. Am J Respir Crit Care Med. 2018; 197(6): 757767, doi: 10.1164/rccm.201706-1172OC, indexed in Pubmed: 29161116.

83. Lansbury LE, Rodrigo C, Leonardi-Bee Jo, et al. Corticosteroids as adjunctive therapy in the treatment of influenza Cochrane Database Syst Rev. 2019; 2(2): CD010406-e9e106, doi: 10.1002/14651858.CD010406.pub3, indexed in Pubmed: $\underline{30798570 .}$.

84. Villar J, Confalonieri M, Pastores SM, et al. Rationale for prolonged corticosteroid treatment in the acute respiratory distress syndrome caused by coronavirus disease 2019. Crit Care Explor. 2020; 2(4): e0111, doi: 10.1097/ CCE.0000000000000111, indexed in Pubmed: 32426753.

85. Russell B, Moss C, Rigg A, et al. COVID-19 and treatment with NSAIDs and corticosteroids: should we be limiting their use in the clinical setting? Ecancermedicalscience. 2020; 14: 1023, doi: 10.3332/ecancer.2020.1023, indexed in Pubmed: 32256706.

86. Jawhara S. Could intravenous immunoglobulin collected from recovered coronavirus patients protect against COVID-19 and strengthen the immune system of new patients? Int J Mol Sci. 2020; 21(7), doi: 10.3390/ijms21072272, indexed in Pubmed: $\underline{32218340 .}$. 
87. Hofmann H, Pyrc K, van der Hoek L, et al. Human coronavirus NL63 employs the severe acute respiratory syndrome coronavirus receptor for cellular entry. Proc Natl Acad Sci U S A. 2005; 102(22): 7988-7993, doi: 10.1073/pnas.0409465102, indexed in Pubmed: 15897467.

88. Pyrc K, Bosch BJ, Berkhout B, et al. Inhibition of human coronavirus NL63 infection at early stages of the replication cycle. Antimicrob Agents Chemother. 2006; 50(6): 2000-2008, doi: 10.1128/AAC.01598-05, indexed in Pubmed: 16723558.

89. Boukhvalova M, Blanco JCG, Falsey AR, et al. Treatment with novel RSV Ig RI-002 controls viral replication and reduces pulmonary damage in immunocompromised Sigmodon hispidus. Bone Marrow Transplant. 2016; 51(1): 119-126, doi: 10.1038/bmt.2015.212, indexed in Pubmed: 26367224.

90. Coomes EA, Haghbayan H. Interleukin-6 in COVID-19: A systematic review and meta-analysis. Rev Med Virol. 2020; 30(6): 1-9, doi: $10.1002 / \mathrm{rmv} .2141$, indexed in Pubmed: 32845568.

91. Zhou F, Yu T, Du R, et al. Clinical course and risk factors for mortality of adult inpatients with COVID-19 in Wuhan, China: a retrospective cohort study. Lancet. 2020; 395(10229): 1054-1062, doi: 10.1016/S0140-6736(20)30566-3, indexed in Pubmed: 32171076.

92. Liu B, Li M, Zhou Z, et al. Can we use interleukin-6 (IL-6) blockade for coronavirus disease 2019 (COVID-19)-induced cytokine release syndrome (CRS)? J Autoimmun. 2020; 111 102452, doi: 10.1016/j.jaut.2020.102452, indexed in Pubmed: 32291137.

93. Kaye AG, Siegel R. The efficacy of IL-6 inhibitor Tocilizumab in reducing severe COVID-19 mortality: a systematic review. PeerJ. 2020; 8: e10322, doi: 10.7717/peerj.10322, indexed in Pubmed: 33194450.

94. MOH-ACE COVID-19 RAPID REVIEW. Should interleukin-6 (IL-6) inhibitors be used for COVID-19? Available online: www.moh.gov.sg/docs/librariesprovider5/clinical-evidence-summaries/il-6-inhibitors-for-covid-19- (updated-2-july-2020)9a9870f958f4409c9ca450a30502d552.pdf. [Last accessed: 12.09.2020].

95. Araújo R, Aranda-Martínez JD, Aranda-Abreu GE. Amantadine treatment for people with COVID-19. Arch Med Res. 2020; 51(7): 739-740, doi: 10.1016/j.arcmed.2020.06.009, indexed in Pubmed: 32571606.

96. Abreu GE, Aguilar ME, Covarrubias DH, et al. Amantadine as a drug to mitigate the effects of COVID-19. Med Hypotheses. 2020; 140: 109755, doi: 10.1016/j.mehy.2020.109755, indexed in Pubmed: $\underline{2361100 .}$

97. Jiménez-Jiménez FJ, Alonso-Navarro H, García-Martín E, et al. Anti-Inflammatory effects of amantadine and memantine: possible therapeutics for the treatment of covid-19? J Pers Med. 2020; 10(4), doi: 10.3390/jpm10040217, indexed in Pubmed: $\underline{33182350 .}$.

98. Paranjpe I, Fuster V, Lala A, et al. Association of treatment dose anticoagulation with in-hospital survival among hospitalized patients with COVID-19. J Am Coll Cardiol. 2020; 76(1): 122-124, doi: 10.1016/j.jacc.2020.05.001, indexed in Pubmed: 32387623

99. Tang N, Bai H, Chen X, et al. Anticoagulant treatment is associated with decreased mortality in severe coronavirus disease 2019 patients with coagulopathy. J Thromb Haemost. 2020; 18(5): 1094-1099, doi: 10.1111/ith.14817, indexed in Pubmed: $\underline{32220112}$

100. National Institutes of Health. COVID-19 Treatment Guidelines Panel. Coronavirus Disease 2019 (COVID-19) Treatment Guidelines. Available online: https://covid19treatmentguidelines.nih.gov. [Last accessed at: 25.09.2020].

101. Szolnoky G. Sulodexide may be a real alternative to low molecular weight heparins in the prevention of COVID-19 induced vascular complications. Dermatol Ther. 2020; 33(6): e14437, doi: 10.1111/dth.14437, indexed in Pubmed: 33078864.

102. Coccheri S, Mannello F. Development and use of sulodexide in vascular diseases: implications for treatment. Drug Des Devel Ther. 2013; 8: 49-65, doi: 10.2147/DDDT.S6762, indexed in Pubmed: 24391440.

103. NIH: ClinicalTrials.gov. Suloexide in the Treatment of Early Stages of COVID-19. Available online: https://clinicaltrials.
gov/ct2/show/NCT04483830. [Last accessed at: 25.09.2020]

104. Bikdeli B, Chatterjee S, Kirtane AJ, et al. Sulodexide versus control and the risk of thrombotic and hemorrhagic events: meta-analysis of randomized trials. Semin Thromb Hemost 2020; 46(8): 908-918, doi: 10.1055/s-0040-1716874, indexed in Pubmed: 33086402.

105. Wu Z, McGoogan JM. Characteristics of and important lessons from the coronavirus disease 2019 (COVID-19) outbreak in China: summary of a report of 72314 cases from the Chinese Center for Disease Control and Prevention. JAMA. 2020; 323(13): 1239-1242, doi: 10.1001/jama.2020.2648, indexed in Pubmed: $\underline{32091533}$.

106. NIH: Oxygenation and ventilation. Available online: www. covid19treatmentguidelines.nih.gov/critical-care/oxygenation-and-ventilation/. [Last accessed at: 25.09.2020].

107. Xu XP, Zhang XC, Hu SL, et al. Noninvasive ventilation in acute hypoxemic nonhypercapnic respiratory failure: a systematic review and meta-analysis. Crit Care Med. 2017; 45(7): e727-e733, doi: 10.1097/CCM.0000000000002361, indexed in Pubmed: 28441237

108. Agarwal A, Basmaji J, Muttalib F, et al. High-flow nasal cannula for acute hypoxemic respiratory failure in patients with COVID-19: systematic reviews of effectiveness and its risks of aerosolization, dispersion, and infection transmission. Can J Anaesth. 2020; 67(9): 1217-1248, doi: 10.1007/s12630-02001740-2, indexed in Pubmed: 32542464.

109. Langford BJ, So M, Raybardhan S, et al. Bacterial co-infection and secondary infection in patients with COVID-19: a living rapid review and meta-analysis. Clin Microbiol Infect. 2020; 26(12): 1622-1629, doi: 10.1016/i.cmi.2020.07.016, indexed in Pubmed: 32711058.

110. Contou D, Claudinon A, Pajot O, et al. Bacterial and viral co-infections in patients with severe SARS-CoV-2 pneumonia admitted to a French ICU. Ann Intensive Care. 2020; 10(1): 119, doi: 10.1186/s13613-020-00736-x, indexed in Pubmed: 32894364 .

111. Aslam B, Wang W, Arshad MI, et al. Antibiotic resistance: a rundown of a global crisis. Infect Drug Resist. 2018; 11: 1645-1658, doi: 10.2147/IDR.S173867, indexed in Pubmed: 30349322.

112. SARS-CoV-2 (Severe acute respiratory syndrome coronavirus 2) Sequences. Available online: www ncbi nlm nih gov/genbank/sars-cov-2-seqs/. [Last accessed at: 23.09.2020].

113. Draft landscape of COVID-19 candidate vaccines. Available online: www.who.int/who-documents-detail/draft-landscape-of-covid-19-candidate-vaccines. [Last accessed at: 26.09.2020].

114. Chinese Clinical Trial Register. Chengdu (Sichuan): Ministry of Health (China). Identifier ChiCTR2000031781, A randomized, double-blinded, placebo-controlled phase II clinical trial for Recombinant Novel Coronavirus (2019-nCOV) Vaccine (Adenovirus Vector). Available at: www.chictr.org.cn/showprojen.aspx?proj=52006. [Last accessed at: 25.09.2020].

115. Moderna Receives FDA Fast Track Designation for mRNA Vaccine (mRNA-1273) Against Novel Coronavirus. ModeRNA Therapeutics website. Available online: https://investors. modernatx.com/news-releases/news-release-details/moderna-receives-fda-fast-track-designation-mrna-vaccine-mrna. [Last accessed at: 26.09.2020].

116. Chinese Clinical Trial Register. Chengdu (Sichuan): Ministry of Health (China). Identifier ChiCTR2000031809 (2020) A randomized, double-blind, placebo parallel-controlled phase I/II clinical trial for inactivated Novel Coronavirus Pneumonia vaccine (Vero cells). Available online: www.chictr.org.cn/ showprojen.aspx?proj=52227. [Last accessed at: 25.09.2020].

117. ClinicalTrials.gov. Bethesda (MD): National Library of Medicine (US). Identifier NCT04383574 (2020) Safety and Immunogenicity Study of Inactivated Vaccine for Prevention of SARS-CoV-2 Infection (COVID-19). Available online: https://clinicaltrials.gov/ct2/show/NCT04383574?term = covid $-19 \&$ cond $=$ vaccine $\&$ cntry $=\mathrm{CN} \& d$ raw $=2 \&$ rank $=3$. [Last accessed at: 25.09.2020]. gov/ct2/show/NCT04383574? ter$\mathrm{m}=$ covid-19\&cond $=$ vaccine \&cntry $=\mathrm{CN} \& d \mathrm{draw}=2 \& \mathrm{rank}=3$ Accessed. 2020; 25: Sept.

118. ClinicalTrials.gov. Bethesda (MD): National Library of Medicine (US). Identifier NCT04336410 (2020) Safety, Tolerability 
and Immunogenicity of INO-4800 for COVID-19 in Healthy Volunteers. Available online: https://clinicaltrials.gov/ct2/show/ NCT04336410. [Last accessed at: 25.09.2020]. https://clinicaltrials gov/ct2/show/NCT04336410 Accessed. 2020; 26: Sept.

119. Smith TRF, Patel A, Ramos S, et al. Immunogenicity of a DNA vaccine candidate for COVID-19. Nat Commun. 2020; 11(1): 2601, doi: 10.1038/s41467-020-16505-0, indexed in Pubmed: 32433465 .

120. ClinicalTrials.gov. Bethesda (MD): National Library of Medicine (US). Identifier NCT04368988 (2020) Evaluation of the Safety and Immunogenicity of a SARS-CoV-2 rS (COVID-19) Nanoparticle Vaccine With/Without Matrix-M Adjuvant. Available online: https://clinicaltrials.gov/ct2/ show/study/NCT04368988?term $=$ vaccine\&recrs $=$ a\&cond $=$ covid-19\&draw $=2 \& \mathrm{rank}=1$. [Last accessed at: 25.09.2020]. Accessed on. 2020; 26: Sept.

121. Chen WH, Chag SM, Poongavanam MV, et al. Optimization of the production process and characterization of the yeast-expressed sars-cov recombinant receptor-binding domain (RBD219-N1), a SARS vaccine candidate. J Pharm Sci. 2017; 106(8): 1961-1970, doi: 10.1016/j.xphs.2017.04.037, indexed in Pubmed: 28456726.

122. Agnihothram S, Gopal R, Yount BL, et al. Evaluation of serologic and antigenic relationships between Middle Eastern respiratory syndrome coronavirus and other coronaviruses to develop vaccine platforms for the rapid response to emerging coronaviruses. J Infect Dis. 2014; 209(7): 995-1006, doi: 10.1093/infdis/jit609, indexed in Pubmed: 24253287.

123. Yong CY, Ong HK, Yeap SK, et al. Recent advances in the vaccine development against Middle East respiratory syndrome-coronavirus. Front Microbiol. 2019; 10: 1781, doi: 10.3389/fmicb.2019.01781, indexed in Pubmed: 31428074.

124. Chan JFW, Kok KH, Zhu Z, et al. Genomic characterization of the 2019 novel human-pathogenic coronavirus isolated from a patient with atypical pneumonia after visiting Wuhan. Emerg Microbes Infect. 2020; 9(1): 221-236, doi: 10.1080/22221751.2020.1719902, indexed in Pubmed: 31987001.

125. Yuan Y, Cao D, Zhang Y, et al. Cryo-EM structures of MERS$\mathrm{CoV}$ and SARS-CoV spike glycoproteins reveal the dynamic receptor binding domains. Nat Commun. 2017; 8: 15092, doi: 10.1038/ncomms15092, indexed in Pubmed: 28393837.

126. Zhang J, Zeng H, Gu J, et al. Progress and prospects on vaccine development against SARS-CoV-2. Vaccines (Basel). 2020; 8(2), doi: 10.3390/vaccines8020153, indexed in Pubmed: 32235387.

127. Tai W, He L, Zhang X, et al. Characterization of the receptor-binding domain (RBD) of 2019 novel coronavirus: implication for development of RBD protein as a viral attachment inhibitor and vaccine. Cell Mol Immunol. 2020; 17(6): 613620, doi: 10.1038/s41423-020-0400-4, indexed in Pubmed: 32203189 .

128. Wrapp D, Wang N, Corbett KS, et al. Cryo-EM structure of the 2019-nCoV spike in the prefusion conformation. Science. 2020; 367(6483): 1260-1263, doi: 10.1126/science.abb2507, indexed in Pubmed: $\underline{32075877}$.

129. Lan J, Ge J, Yu J, et al. Structure of the SARS-CoV-2 spike receptor-binding domain bound to the ACE2 receptor. Nature. 2020; 581(7807): 215-220, doi: 10.1038/s41586-020-2180-5, indexed in Pubmed: 32225176.

130. Coleman CM, Liu YeV, Mu H, et al. Purified coronavirus spike protein nanoparticles induce coronavirus neutralizing antibodies in mice. Vaccine. 2014; 32(26): 3169-3174, doi: 10.1016/j. vaccine.2014.04.016, indexed in Pubmed: 24736006.

131. Wang N, Shang J, Jiang S, et al. Subunit vaccines against emerging pathogenic human coronaviruses. Front Microbiol. 2020; 11: 298, doi: 10.3389/fmicb.2020.00298, indexed in Pubmed: $\underline{32265848}$.

132. Ahmed SF, Quadeer AA, McKay MR. Preliminary identification of potential vaccine targets for the COVID-19 coronavirus (sars-cov-2) based on SARS-CoV immunological studies.
Viruses. 2020; 12(3), doi: 10.3390/v12030254, indexed in Pubmed: 32106567.

133. Grifoni A, Sidney J, Zhang Y, et al. A sequence homology and bioinformatic approach can predict candidate targets for immune responses to SARS-CoV-2. Cell Host Microbe. 2020; 27(4): 671-680.e2, doi: 10.1016/j.chom.2020.03.002, indexed in Pubmed: 32183941.

134. Bhattacharya M, Sharma AR, Patra P, et al. Development of epitope-based peptide vaccine against novel coronavirus 2019 (SARS-COV-2): Immunoinformatics approach. J Med Virol. 2020; 92(6): 618-631, doi: 10.1002/imv.25736, indexed in Pubmed: $\underline{32108359}$.

135. Salman S, Salem ML. Routine childhood immunization may protect against COVID-19. Med Hypotheses. 2020 [Epub ahead of print]; 140: 109689, doi: 10.1016/j.mehy.2020.109689, indexed in Pubmed: $\underline{32240961 .}$.

136. Sarialioglu F, Belen Apak FB, Haberal M. Can hepatitis a vaccine provide protection against COVID-19? Exp Clin Transplant. 2020; 18(2): 141-143, doi: 10.6002/ect.2020.0109, indexed in Pubmed: 32279655.

137. Shereen MA, Khan S, Kazmi A, et al. COVID-19 infection: Origin, transmission, and characteristics of human coronaviruses. J Adv Res. 2020; 24: 91-98, doi: 10.1016/j.jare.2020.03.005, indexed in Pubmed: 32257431.

138. Miller A, Reandelar M, Fasciglione K, et al. Correlation between universal BCG vaccination policy and reduced mortality for COVID-19. medRxiv. 2020, doi: 10.1101/2020.03.24.20042937.

139. Redelman-Sidi G. Could BCG be used to protect against COVID-19? Nat Rev Urol. 2020; 17(6): 316-317, doi: 10.1038/ s41585-020-0325-9, indexed in Pubmed: 32341531.

140. ClinicalTrials.gov. National Library of Medicine (US). Identifier NCT04327206 (2020) BCG Vaccination to Protect Healthcare Workers Against COVID-19. Available online: https:// clinicaltrials.gov/ct2/show/study/NCT04327206. [Last accessed at: 25.09.2020].

141. ClinicalTrials.gov. National Library of Medicine (US). Identifier NCT04328441 Reducing Health Care Workers Absenteeism in Covid-19 Pandemic Through BCG Vaccine (BCG-CORONA). Available online: https://clinicaltrials.gov/ct2/show/record/NCT04328441. [Last accessed at: 28.09.2020].

142. Casadevall A, Pirofski LA. The convalescent sera option for containing COVID-19. J Clin Invest. 2020; 130(4): 1545-1548, doi: 10.1172/JCI138003, indexed in Pubmed: 32167489.

143. Bloch EM, Shoham S, Casadevall A, et al. Deployment of convalescent plasma for the prevention and treatment of COVID-19. J Clin Invest. 2020; 130(6): 2757-2765, doi: 10.1172/JCI138745, indexed in Pubmed: 32254064.

144. Wan Y, Shang J, Sun S, et al. Molecular mechanism for antibody-dependent enhancement of coronavirus entry. J Virol. 2020; 94(5), doi: 10.1128/JVI.02015-19, indexed in Pubmed: 31826992.

145. Sanjuán R, Domingo-Calap P. Mechanisms of viral mutation. Cell Mol Life Sci. 2016; 73(23): 4433-4448, doi: $10.1007 /$ s00018-016-2299-6, indexed in Pubmed: 27392606.

146. Elena SF, Sanjuán R. Adaptive value of high mutation rates of RNA viruses: separating causes from consequences. J Virol. 2005; 79(18): 11555-11558, doi: 10.1128/JVI.79.18.1155511558.2005, indexed in Pubmed: 16140732.

147. Centers for Disease Control and Prevention (CDC), 2020. Vaccine Testing and the Approval Process. Available online: www.cdc.gov/vaccines/basics/test-approve.html. [Last accessed at: 29.09.2020].

148. World Health Organization (WHO), 2020. The latest on the COVID-19 global situation \& vaccine development. Available online: www.who.int/docs/default-source/coronaviruse/ risk-comms-updates/update45-vaccines-developement. [Last accessed at: 29.09.2020]

149. Kim JH, Marks F, Clemens JD. Looking beyond COVID-19 vaccine phase 3 trials. Nat Med. 2021; 27(2): 205-211, doi: 10.1038/s41591-021-01230-y, indexed in Pubmed: 33469205. 